\title{
Consideration of HCD Methods for Service Innovation Design
}

\author{
Akira Kondo ${ }^{1}$ and Naoko Kondo ${ }^{2}$ \\ ${ }^{1}$ Hitachi Intermedix Co., Ltd. \\ 2-1-5 Kandanishikicho, Chiyodaku, Tokyo, 101-0054 Japan \\ kondo@hipri.com \\ ${ }^{2}$ OpensourceCRM, Inc. \\ UtokuTamachi Bldg., 2-13-7 Shibaura, Minato-ku, Tokyo 108-0023, Japan \\ kondo@osscrm.com
}

\begin{abstract}
In modern society the service industry has took main role in advanced countries and the service innovation, how to design to improve productivity of the service, become a major issue in the business world. The service has four features as intangible, concurrency, heterogeneity, and extinction, then the service design process and perspective are considered to be different from the product design in the industrial age. When we build the service business, we should think about service elements such as a service receiver, a service provider, field of services, and time axis, in comprehensive viewpoint. In the service industry, we have to provide the service to satisfy customers, but it is necessary to understand the varying needs of different customers. Traditionally this process is relied on the ability of the person providing the service. The improvement of the service productivity was depends on the individual's tacit knowledge in the large part, there are also limits of human ability, then it is difficult to generalize. On the other hand, modern Web services that are provided through the internet, information processing technology could be speculated the information needs of users through the human computer interaction, it has become possible to improve the service productivity. In this paper, in order to achieve improved the service productivity by information technology services, and we considered how to embody changeable user desires as explicit knowledge using the human-centered design techniques. As a concrete methodology, in order to systematically understand the varying needs of users, is considered to be a ethnography and contextual inquiry method, as output in order to incorporate the inference engine need to be written as a structured form. As for the psychological needs of users, I think it is appropriate to consider developing a persona, the issue is a how to build a appropriate emotional model. What may be modeled using the technique of human-centered design to the desire for services that change these users, such as shops electrons on the current Internet, analyze the user's preferences, select the information that may be of interest for each user show to take a case recommendation service system, and consider.
\end{abstract}

Keywords: Service Innovation, Human Centered Design. 


\section{Introduction}

In industrialized society, the main economic activity was trading products. That time, the service was associated with products. But now the customer wants, not just get good products, comfortable process of trading, and favorable experience using products. In retail trade service, as well as the actual value of products, customer service attitude, store image, product line, and appropriate products information are affecting customer satisfaction. Usui advocates that the following four perspectives are important for retail trade service.

- Providing information and prior expectations

- Provision of products and services themselves

- The quality of providing process

- Duration of follow-up and provide satisfaction

Then we should think about not a provider perspective, but it is important to the customer's perspective in service design.

The other hand, implementing ICT in service process are getting that aiming at improving the productivity in the service market. Retail business market continues to expand ecommerce. As a result, many companies try to refine their service to get good position in the market. Then such companies start to take in HCD (HumanCentered Design) process.

In Japan, the government launch e-government usability guideline to satisfy most user. This guideline introduces the useful e-government website and system building process by HCD methods.

Thus, the expanding Internet services market has been focused on the need for HCD process.

\section{Purpose of Research}

With the expansion of the Internet services market it is necessary to provide services to various users via the Internet. Traditional service contact point was person but such a current service, PC or tablet, and mobile phone interface become a new contact point. Service Business on the Internet, not just simply replace the traditional service delivery models into internet fields, service provider should think about such as service innovation to improve productivity and customer satisfaction.

In this paper, first we survey the concept of service innovation to improve the productivity of services.

Then, as a concrete case of service innovation, we investigate in ecommerce recommendation system that aim at consider about ICT based service delivery issues. At the last part, we consider how we can use a HCD approach in service design and discuss its effectiveness. 


\section{Survey of Service Innovation}

\subsection{Definition of Innovation from Economic View Point}

In Japan, many people think that "Innovation" means "Technological Revolution." However famous economist Joseph Schumpeter defined economic innovation as follows;

- The introduction of a new good - that is one with which consumers are not yet familiar - or of a new quality of a good.

- The introduction of a new method of production, which need by no means be founded upon a discovery scientifically new, and can also exist in a new way of handling a commodity commercially.

- The opening of a new market, that is a market into which the particular branch of manufacture of the country in question has not previously entered, whether or not this market has existed before.

- The conquest of a new source of supply of raw materials or half-manufactured goods, again irrespective of whether this source already exists or whether it has first to be created.

- The carrying out of the new organization of any industry, like the creation of a monopoly position (for example through trustification) or the breaking up of a monopoly position

We have this definition in mind we survey the service innovation as "the service deliver new value."

\subsection{Activity of "Service Industry Productivity Council" in Japan}

"Service Industry Productivity Council" is Japanese cooperative research groups consisting of experts from universities and companies. They announced the award to companies and organizations doing innovative work to help improve innovation and productivity. They evaluate companies and organizations efforts from the following perspective.

- Scientific and engineering approaches

- Improvement Services Process

- High value-added services

- Human resource development

- International Expansion

- Regional contribution

I think these perspectives are almost close to Schumpeter's Innovation definition. This award also intend to introduce the importance of ICT and HCD process to build good service value chain.

\subsection{Direction of Service Innovation}

From the previous literature survey, it is necessary to design a new value procreation service value chain to realize service innovation. On its way, Takada and Koike 
analyzed that following directions are important, "Building the Web service value" for including creating a value chain for service, and "Module Development Services ", "Improvement of service interaction, "" development, utilization, service platform "for having both way diversity and standardization. The creating a value chain for service is dependent on the part of basic service delivery, so in this study we focus on having both way diversity and standardization, particularly "Improvement of service interaction."

As cases of "Improvement of service interaction," the report introduced "financial aggregation" that means the office handles a variety of financial products, and "tailormade service" that is fabricated a personal computer using a direct order from user. This direction of service innovation to achieve this service the needs of various customers, as embodied by the appropriate interaction mechanism. Present in ecommerce "Improvement of service interaction" realized as a system, the recommendation system to be an example case.

\section{Case Study}

\subsection{Recommendation System Theories and Issues}

Ecommerce market is expanding, many EC site provide the recommendation system for user to find products from various products. However, there are findings that user feel disgusting recommendations because of unknown system data processing. The current recommendation systems have been constructed by following methods "rules based," "content based," "collaborative filtering," and "Bayesian network." Most methods are showing items those are selected from the user's action history. These recommendation theories, the following problems were identified was conducted user interviews.

- Not meet the user's intention to buy the relevant product recommendations

- Feel uncomfortable used historical data without permission

- Items appear that user have purchased products or not want

We consider about this issue from "Model of service quality gaps (Parasuraman et al., 1985; Curry, 1999; Luk and Layton, 2002)." As a result, service gaps have become obvious in GAP1 and GAP5 in the current ecommerce. So we analyze that there are no inconsistent within the service provider side but in reality service are not meet user expectations and service provider attempt. In addition, we consider that a service provider have not investigated about management system to correct these service gaps.

\subsection{Improvement Proposal of Recommendation System by HCD}

We consider how to use HCD method in development process of recommendation system in Fig 2.

We presented the scenario of improved recommendation service by HCD methods to subjects then they express positive response. So we believe that HCD process is effective for service innovation powered by ICT such as recommendation system. 




Fig. 1. Model of service quality gaps and HCD methods (Kondo revised from original fig. by Parasuraman et al., 1985; Curry, 1999; Luk and Layton, 2002)

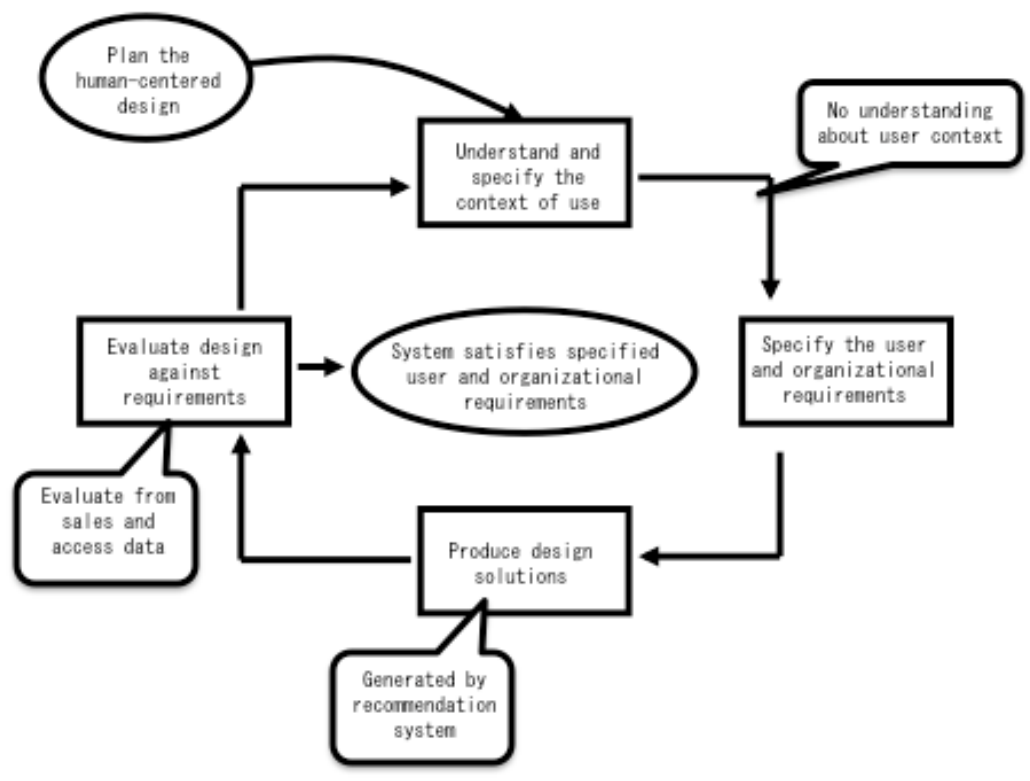

Fig. 2. HCD development process for the recommendation system 


\section{Future Agenda}

Service innovation will not be brought by HCD methods but collaboration work with system developers, UX designers and other specialists. Then we would like to survey various cases to find appropriate team and methods for service innovation.

The other hand, we need to consider about service business sustainability. In this business perspective, service design process should establish a cooperative mechanism with business management methods. So we proposed this service business methods flame and investigate efficiency.

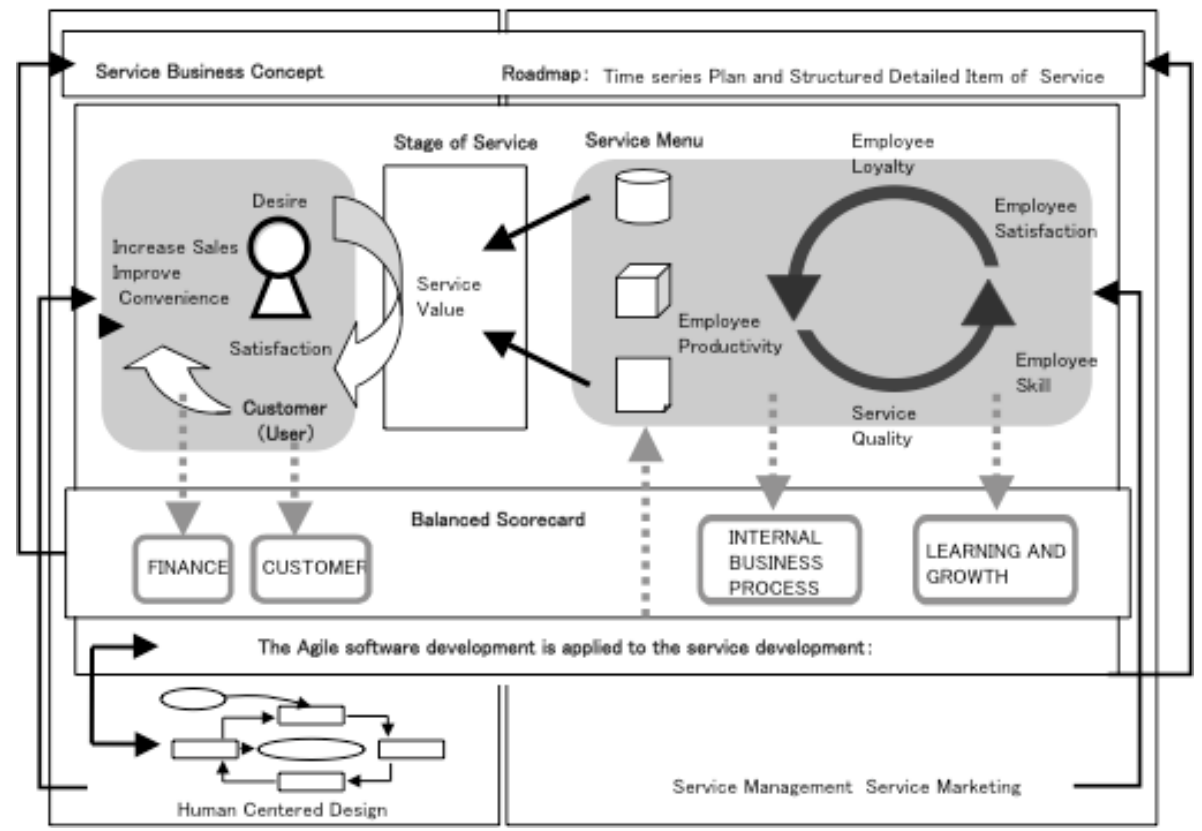

Fig. 3. Service design methods flame

\section{References}

[1] Makoto Usui, Promote Service Innovation, Nikkei IT Pro Website, Japanese (2009), http://itpro.nikkeibp.co.jp/article/COLUMN/20090529/330954/

[2] Cabinet Secretariat, Usability e-Government Guideline, Japanese (2009), http://www.kantei.go.jp/jp/singi/it2/guide/security/kaisai_ h21/dai37/h210701gl.pdf

[3] Schumpeter, J.: The Theory of Economic Development. Harvard University Press, Boston (1934)

[4] Service Industry Productivity Council, High Service Best 300 in Japan Website (20072010) (Japanese), http://www.service-js.jp/cms/page0600.php 
[5] Takada, T., Koike, K.: Service Innovation of Japanese Companies. Creation of intellectual property (CHITEKISHISANSOUZOU in Japanese). Nomura Research Institute Ltd., Japan (2002)

[6] KDDI R\&D Laboratories, Successful elucidation of receptor structure recommended services using personal information, News Release Website (2010), http: / / www . kddilabs.jp/press /img/154_1.pdf

[7] Carroll, J.M.: Scenario-based Design envisioning work and technology in system development. Wiley, US (1996)

[8] Carroll, J.M.: Making Use of Scenario-based design of human-computer interactions. The MIT Press, US (2000)

[9] Kondo, A., Kondo, N.: Research of Design Method for Service Business Development. In: 2nd International Service Innovation Design Conference, Hakodate Japan (2010)

[10] Yamazaki, K., Furuta, K.: Proposal for design method considering user experience. In: 11th International Conference on Human-Computer Interaction, Las Vegas (2005)

[11] Kameoka, A.: Service Science (Japanese), NTS, Inc., Japan (2007) 